\title{
The Problem of Negatives Generated by the Commodity Technology Model in Input-Output Analysis: A Review of the Solutions
}

\author{
Thijs ten Raa $\cdot$ José Manuel Rueda-Cantuche
}

Received: 7 January 2013 / Accepted: 18 April 2013 / Published online: 2 May 2013

(C) 2013 T. ten Raa, J.M. Rueda-Cantuche; licensee Springer. This is an Open Access article distributed under the terms of the Creative Commons Attribution License

(http://creativecommons.org/licenses/by/2.0), which permits unrestricted use, distribution, and

reproduction in any medium, provided the original work is properly cited.

\begin{abstract}
Many economic models (e.g., computable general equilibrium models, econometric input-output models) revolve around a matrix of technical coefficients. However, these matrices can be estimated only once every 5 years as long as they are calculated from input-output tables and these are only published on a 5-year basis. Alternatively, use and make (or supply) tables are being regularly published on a yearly basis. However, they need to be converted into input-output tables as a previous step to form the matrix of technical coefficients. In doing so, this paper aims to shed light on the construction process of input-output tables and to guide economic modelers in making a decision on the way to make such conversion and how to deal with the subsequent problems, particularly with negative technical coefficients.
\end{abstract}

Keywords Input-output analysis - Technical coefficients - Use and make tables · Input-output modeling

\section{JEL Classification C67 · D57}

\section{Introduction}

Many economic models (e.g., computable and/or applied general equilibrium models, econometric input-output models) revolve around a matrix of technical coefficients, the amounts of commodities $i$ used for the production of units of commodi-

\footnotetext{
T. ten Raa

Department of Econometrics and Operations Research, Tilburg University, P.O. Box 90153, 5000

LE, Tilburg, The Netherlands

e-mail: tenRaa@UvT.nl

J.M. Rueda-Cantuche ( $\varangle)$

Department of Economics, Quantitative Methods and Economic History, Pablo de Olavide

University, Carretera de Utrera km. 1, 41013, Seville, Spain

e-mail: jmruecan@upo.es
} 
ties $j .{ }^{1}$ These matrices can be derived directly from input-output tables, which, however, tend to be published every 5 years only (e.g., Eurostat), or indirectly from annually published use and make (or supply) tables, which describe the use of commodities by industries, households, government and the foreign sector, and the production of commodities by industry, respectively. The indirect construction of a technical coefficients matrix essentially removes secondary activities from industries, and this procedure may create negative input coefficients. We review variants of this procedure and the ways negative coefficients are circumvented.

Some farmers produce cheese as a secondary activity; the farmers' input structure of their main activity is distorted by the inputs of cheese. These inputs must be removed somehow, shifted to the cheese industry. There are two removal procedures, employing the input structure of the farmers who produce cheese (admitting that cheese can be produced differently in different industries) or of the cheese manufacturing industry. The former option is denoted as the industry technology assumption, while the latter is denoted as the commodity technology assumption. This paper will give insight in the pros and cons of the two options. The next section introduces a common framework encompassing the commodity and industry technology assumptions and also identifies the former as theoretically superior according to the existent literature. However, Sect. 3 identifies sources of potential negative technical coefficients that plague the commodity technology assumption. In Sect. 4, we provide a comprehensive review of the procedures available in the literature to deal with these negatives, both for square and rectangular use and make tables. We conclude with some guidelines for economic modelers.

\section{Background Context}

The theoretically superior method for the construction of technical coefficients, the so-called commodity technology model, is plagued by the problem that it generates negative results. This explains the continuing popularity of the main competing method, the industry technology model, also as a basis for modifications of the commodity technology model. ten Raa and Rueda-Cantuche [25] presented an encompassing framework ${ }^{2}$ for both models, which will be used to review the sources of negative coefficients and the procedures that have been proposed to remove them.

It is a bit surprising that an encompassing formula exists. After all, the industry and commodity technology models are very different. The industry technology model takes weighted averages of industry coefficients, where the latter are defined by dividing inputs by total industry output. The weights are market shares and the consequent commodity input coefficients are simple and nonnegative. The commodity technology model, however, involves an inversion of the output matrix. Commodity input

\footnotetext{
${ }^{1}$ We are aware that industry-by-industry input-output tables can also lead to the construction of a matrix of input coefficients, but these are not generally conceived as matrices of technical coefficients; therefore, they will not be discussed in this paper.

${ }^{2}$ Later on, Rueda-Cantuche and ten Raa [18] presented a similar encompassing framework for the two other methods used in the construction of industry-by-industry input-output tables.
} 
coefficients are postulated and for each industry the implied input demand vector is equated with the observed use vector; a system of equations must be solved.

Following the United Nations System of National Accounts [28, 29] consider a use matrix $\mathbf{U}=\left(u_{i j}\right)_{i, j=1, \ldots, n}$ comprising commodities $i$ consumed by sectors $j$, and a make matrix $\mathbf{V}=\left(v_{i j}\right)_{i, j=1, \ldots, n}$ showing the produce of sectors $i$ in terms of commodities $j$. The problem of negatives is a problem of the commodity technology model, which, in deterministic form, requires square tables, with the same number of commodities as of industries. The issue is the derivation of input coefficients $\left(a_{i j}\right)$. In other words, how can we estimate the amount of commodity $i$ used for the production of one unit of commodity $j$ ? If there are more commodities than industries, the commodity technology model cannot be implemented; the industry technology model can-it yields no negatives but has other problems [13]. If there more industries than commodities, the commodity technology model admits stochastic analysis; it still yields negatives, but we leave the analysis for future research.

Following ten Raa and Rueda-Cantuche [25], our point of departure is the amount of commodity $i$ used by industry $j\left(u_{i j}\right)$. The basic idea, common to the main methods of construction, is to subtract from $u_{i j}$ the consumptions of commodity $i$ used by industry $j$ for its secondary products, $k \neq j$. The problem is that secondary outputs of industry $j$ do not necessarily have the same input structure as in the industries where they are primary output. The flipside of the coin is that to compute the average input requirements of commodity $j$, we must $a d d$ the secondary output to $v_{j j}$ and the associated inputs to $u_{i j}$. The total input requirements of commodity $i$ for making commodity $j$ (as a single product) are thus:

$$
u_{i j}-\sum_{\substack{k=1 \\ k \neq j}}^{n} a_{i j k} v_{j k}+\sum_{\substack{k=1 \\ k \neq j}}^{n} a_{i k j} v_{k j}
$$

where $a_{i j k}$ is the amount of commodity $i$ used by industry $j$ for making a unit of commodity $k$. Dividing by the total output of commodity $j$, we obtain our general formula for technical coefficients:

$$
a_{i j}=\frac{u_{i j}-\sum_{k=1, k \neq j}^{n} a_{i j k} v_{j k}+\sum_{k=1, k \neq j}^{n} a_{i k j} v_{k j}}{\sum_{k=1}^{n} v_{k j}} .
$$

We shall now show how this formula encompasses the main constructs of the literature, namely the commodity technology model and the industry technology model. In what follows, e will denote a column vector with all entries equal to one, ${ }^{\mathrm{T}}$ will denote transposition and ${ }^{-1}$ inversion of a matrix. Since the latter two operations commute, their composition may be denoted ${ }^{-\mathrm{T}}$. Also, ${ }^{-}$will denote diagonalization, whether by suppression of the off-diagonal elements of a square matrix or by placement of the elements of a vector. $\sim$ will denote a matrix with all the diagonal elements set to zero.

The commodity technology model assumes that all commodities have the same inputs structure irrespective the industry of fabrication:

$$
a_{i j k}=a_{i k}, \quad \forall j=1,2, \ldots, n .
$$


Therefore, (1) becomes:

$$
a_{i j}=\frac{u_{i j}-\sum_{k=1, k \neq j}^{n} a_{i k} v_{j k}+\sum_{k=1, k \neq j}^{n} a_{i j} v_{k j}}{\sum_{k=1}^{n} v_{k j}},
$$

which, in matrix terms, is:

$$
\begin{aligned}
\mathbf{A} & =\left(\mathbf{U}-\mathbf{A} \tilde{\mathbf{V}}^{\mathrm{T}}+\mathbf{A}\left(\widehat{\widetilde{\mathbf{V}}^{\mathrm{T}}} \mathbf{e}\right)\right)\left(\widehat{\mathbf{V}^{\mathrm{T}}} \mathbf{e}\right)^{-1} \\
& =\left(\mathbf{U}-\mathbf{A} \widetilde{\mathbf{V}}^{\mathrm{T}}+\mathbf{A}\left(\widetilde{\mathbf{V}^{\mathrm{T}}} \mathbf{e}\right)\right)\left(\widehat{\mathbf{V} e}+\left(\widehat{\mathbf{V}^{\mathrm{T}}} \mathbf{e}\right)-\widehat{\mathbf{V}} \mathbf{e}\right)^{-1},
\end{aligned}
$$

and operating with (3), it yields

$$
\begin{aligned}
\mathbf{U}-\mathbf{A} \tilde{\mathbf{V}}^{\mathrm{T}}+\mathbf{A}\left(\widehat{\widetilde{\mathbf{V}}^{\mathrm{T}} \mathbf{e}}\right) & =\mathbf{A}\left(\widehat{\mathbf{V}^{\mathrm{T}} \mathbf{e}}\right) \\
& =\mathbf{A}\left(\widehat{\mathbf{V e}}+\left(\widetilde{\mathbf{V}^{\mathrm{T}} \mathbf{e}}\right)-\widehat{\mathbf{V} e}\right)=\mathbf{A} \widehat{\mathbf{V e}}+\mathbf{A}\left(\widetilde{\mathbf{V}^{\mathrm{T}}} \mathbf{e}\right)-\mathbf{A}(\widehat{\mathbf{V} e}),
\end{aligned}
$$

which is the same as

$$
\mathbf{U}-\mathbf{A} \widetilde{\mathbf{V}}^{\mathrm{T}}=\mathbf{A} \widehat{\mathbf{V e}}-\mathbf{A}(\widehat{\widetilde{\mathbf{V e}}})=\mathbf{A}(\widehat{\mathbf{V e}}-\widehat{\widetilde{\mathbf{V e}}})=\mathbf{A}(\widehat{\mathbf{V e}-\widetilde{\mathbf{V}} \mathbf{e}})=\mathbf{A}(\widehat{\widehat{\mathbf{V e}}})=\mathbf{A} \widehat{\mathbf{V}}^{\mathrm{T}}
$$

and

$$
\mathbf{U}=\mathbf{A} \tilde{\mathbf{V}}^{\mathrm{T}}+\mathbf{A} \widehat{\mathbf{V}}^{\mathrm{T}}=\mathbf{A}\left(\widetilde{\mathbf{V}}^{\mathrm{T}}+\widehat{\mathbf{V}}^{\mathrm{T}}\right)=\mathbf{A} \mathbf{V}^{\mathrm{T}}
$$

Consequently, $\mathbf{A}=\mathbf{U} \mathbf{V}^{-\mathrm{T}}$. Notice that technical coefficients can be negative when the total consumption of input $i$ for the making of secondary outputs of industry $j$, according to each one of these commodity technologies, is larger than the total use of commodity $i$ by the industry $j$, either for its primary or secondary products. Following the example in Sect. 1, a negative coefficient would arise if farmers were producing cheese with their own milk only instead of purchasing it elsewhere. Indeed, the input structure of the manufacturing industry of cheese would use milk as an input while farmers would not; subtraction of the inputs associated with the secondary production of cheese (using the commodity technology assumption) from the current mixed farmers' input structure yields a negative input coefficient.

The industry technology model assumes that all industries have the same inputs structure irrespective of the commodities they produce. This means that

$$
a_{i j k}=a_{i j}, \quad \forall k=1,2, \ldots, n .
$$

Hence, (1) becomes into

$$
a_{i j}=\frac{u_{i j}-\sum_{k=1, k \neq j}^{n} a_{i j} v_{j k}+\sum_{k=1, k \neq j}^{n} a_{i k} v_{k j}}{\sum_{k=1}^{n} v_{k j}},
$$

which, in matrix terms, is

$$
\mathbf{A}=(\mathbf{U}-\mathbf{A}(\widehat{\mathbf{V} e})+\mathbf{A} \tilde{\mathbf{V}})\left(\widehat{\mathbf{V}^{\mathrm{T}} \mathbf{e}}\right)^{-1}
$$


and operating (4) properly,

$$
\mathbf{U}=\mathbf{A}\left(\widehat{\mathbf{V}^{\mathrm{T}} \mathbf{e}}\right)+\mathbf{A}(\widetilde{\mathbf{V} e})-\mathbf{A} \widetilde{\mathbf{V}}=\mathbf{A}\left(\widehat{\mathbf{V}^{\mathrm{T}} \mathbf{e}}+\widehat{\widetilde{\mathbf{V}} \mathbf{e}}-\tilde{\mathbf{V}}\right)
$$

and

$$
\mathbf{A}=\mathbf{U}\left(\widehat{\mathbf{V}^{\mathrm{T}} \mathbf{e}}+\widehat{\widetilde{\mathbf{V}} \mathbf{e}}-\widetilde{\mathbf{V}}\right)^{-1}=\mathbf{U}\left(\widehat{\mathbf{V}^{\mathrm{T}} \mathbf{e}}+\widehat{\mathbf{V} e}-\mathbf{V}\right)^{-1}
$$

since $\tilde{\mathbf{V}} \mathbf{e}=\mathbf{V e}-\widehat{\mathbf{V}} \mathbf{e}$ and $\tilde{\mathbf{V}}=\mathbf{V}-\widehat{\mathbf{V}}$.

Under the industry technology assumption, no negative technical coefficient can be obtained in (4).

The commodity technology assumption is considered theoretically superior [11, $13,15,16,22,24]$, but agreement is not uniform. For instance, de Mesnard [6] stated that the commodity technology hypothesis has to be rejected since it breaks the linkages of commodity flows internal to the industries. No information is available to determine which industry supplies a positive variation in final demand of a particular commodity. de Mesnard suggests that the industry technology model may be preferred even though it violates some axioms of Kop Jansen and ten Raa [13].

\section{Sources of Negative Coefficients}

Commodity technology model based coefficients may be negative for a number of reasons.

First, some commodities are produced with different technologies $[4,11,15,17$, $26,27]$. In this case, the commodity technology assumption is not valid.

Second, production classifications are heterogeneous [5, 10-12, 15-17, 27].

And third, the use and make data have errors of measurement $[4,5,11,12,14,16$, $22,23,26]$.

In spite of these complications, the handbook of the compilation of input-output tables (UN [30]) recommends the use of the commodity technology assumption. Hence, we must review procedures that have been suggested to remove the negative coefficients.

\section{Removal Procedures}

Since the pioneering work of Edmonston (p. 569 in [7]), several procedures remove the negatives that come with the commodity technology model.

\subsection{Armstrong Procedure [4]}

Armstrong [4] applied a hybrid technology assumption based on Gigantes [8]. Secondary products that yield negatives in the input-output table were subjected to the industry technology assumption. Hybrid methods require that the make matrix is split into two matrices, $\mathbf{V}_{1}$ and $\mathbf{V}_{2}$, where in this case the first one includes outputs for which the commodity technology assumption is made and the second includes those, 
which are to be treated on an industry technology assumption. Particularly, in the United Kingdom (UK) Input-Output Tables for 1963, $55 \%$ of secondary production was treated on the industry technology assumption and the remaining $45 \%$ on the commodity technology hypothesis. However, in some cases, this procedure leads to unacceptable situations. For instance, in [4] other food industries have as secondary outputs distribution services, which have large inputs of printing, while other food industries do not use much of them. Application of the industry technology assumption would result in a large amount of agricultural inputs into distribution services. In such cases disaggregation was adopted.

Formally, industry outputs of commodities for which the commodity technology assumption is made, are proportional to the output of each industry:

$$
\mathbf{V}_{1}^{\mathrm{T}}=\mathbf{C}_{1}\left(\widehat{\mathbf{V}_{1} \mathbf{e}}\right)
$$

and the market shares are denoted by

$$
\mathbf{V}_{2}=\mathbf{D}_{2}^{*}\left(\widehat{\mathbf{V}_{2}^{\mathrm{T}} \mathbf{e}}\right)
$$

Armstrong [4] obtains two variants of technical coefficients matrices, depending on which of the following two assumptions is made. Industry outputs for which an industry technology assumption is made are proportional to the economy-wide outputs of each commodity whatever industry produces them. Commodity outputs for which an industry technology assumption is made are proportional to the economy-wide outputs of the producing industries (pp. 74-76 in [4]). Mathematically, the former assumption is denoted as

$$
\mathbf{V}_{2} \mathbf{e}=\mathbf{D}_{2}\left(\mathbf{V}^{\mathrm{T}} \mathbf{e}\right)
$$

whereas the latter is defined by

$$
\mathbf{V}_{2}^{\mathrm{T}} \mathbf{e}=\mathbf{C}_{2}(\mathbf{V e})
$$

In the UK Input-Output Tables for 1963, Armstrong [4] used the first assumption and the resulting technical coefficients matrix was given by

$$
\mathbf{A}_{\mathbf{H}}(\mathbf{U}, \mathbf{V})=\mathbf{U}(\widehat{\mathbf{V e}})^{-1}\left(\left(\widehat{\mathbf{V e}_{1}}\right) \mathbf{V}_{1}^{-\mathrm{T}}\left(\mathbf{I}-\left(\widehat{\mathbf{V}^{\mathrm{T}}} \mathbf{e}\right)^{-1}\left(\widehat{\mathbf{V}_{2}^{\mathrm{T}} \mathbf{e}}\right)\right)+\mathbf{V}_{2}\left(\widehat{\mathbf{V}^{\mathrm{T}} \mathbf{e}}\right)^{-1}\right)
$$

Nevertheless, there were some remaining negatives that Armstrong [4] set manually to zero or to a slightly positive value adjusting other entries of the input-output table so that overall accounting constraints in rows and columns still remain, as one expects when the commodity technology assumption continues to be used for part of the economy.

\subsection{Almon Procedure [1]}

Almon $[1]^{3}$ devised an iterative method that calculates nonnegative technical coefficients matrices through a commodity-technology based algorithm. It is solved by the

\footnotetext{
${ }^{3}$ Almon first devised this procedure in [1].
} 
Seidel iterative process:

$$
a_{i j}^{(h+1)} \sum_{k=1}^{n} v_{k j}=u_{i j}-\sum_{\substack{k=1 \\ k \neq j}}^{n} a_{i k}^{(h)} v_{j k}+\sum_{\substack{k=1 \\ k \neq j}}^{n} a_{i j}^{(h)} v_{k j} .
$$

Convergence is guaranteed if more than half of the production of a product is in its primary industry. Almon [1] interprets this equation for the use of chocolate $(i)$, in the production of cheese $(j)$. Then "the first term on the right of (5) tells us to begin with the chocolate purchases by the establishments in the cheese industry. The second term directs us to remove the amounts of chocolate needed for making the secondary products of those establishments by using our present estimate of the technology used for making those products, $a_{i k}^{(h)}$. Finally, the last term causes us to add back the chocolate used in making cheese in other industries." However, Almon's claim that the third term is exactly equal to the amount stolen, via second terms, from other industries, is not true. Unless all products are considered and not only cheese, the sum of the two latter terms of the right-hand side of (5) is not necessarily be null. Therefore, only by summing both sides of (5) over $j$, we will obtain the amount of input $i$ used for the making of all products of the economy and not only for cheese (product $j$ ). That is,

$$
\sum_{j=1}^{n}\left(a_{i j}^{(h+1)} \sum_{k=1}^{n} v_{k j}\right)=\sum_{j=1}^{n} u_{i j}-\sum_{j=1}^{n} \sum_{\substack{k=1 \\ k \neq j}}^{n} a_{i k}^{(h)} v_{j k}+\sum_{j=1}^{n} \sum_{\substack{k=1 \\ k \neq j}}^{n} a_{i j}^{(h)} v_{k j}
$$

The second and third terms on the right-hand side of (6) cancel, though not for each product $j$ separately. The next propositions elucidate the emergence of negative coefficients. Other technology assumptions, particularly mixed technology models, can be scrutinized in the same way.

Proposition 1 If $\mathbf{V}$ is nonsingular and nonnegative, the technical coefficients matrix A derived from $\mathbf{U}=\mathbf{A} \mathbf{V}^{\mathrm{T}}$ will yield negative values if and only iffor some product $j$,

$$
u_{i j}<\sum_{\substack{k=1 \\ k \neq j}}^{n} a_{i k}^{(h)} v_{j k}-\sum_{\substack{k=1 \\ k \neq j}}^{n} a_{i j}^{(h)} v_{k j}
$$

In short, when the difference between the amount of chocolate needed for making the secondary products of the cheese industry $(j)$ and the amount of chocolate used by other industries to produce cheese is larger than the total purchases of chocolate by the establishments of the cheese industry (for making either primary or secondary products), negatives arise. The sufficiency proof follows from (5). For the necessity proof, let us assume a given negative technical coefficient, $a_{i j}^{(h+1)}<0$, since 
$\sum_{k=1}^{n} v_{k j}>0$, then $a_{i j}^{(h+1)} \sum_{k=1}^{n} v_{k j}<0$, and bearing in mind (5), it follows that

$$
a_{i j}^{(h+1)} \sum_{k=1}^{n} v_{k j}=u_{i j}-\sum_{\substack{k=1 \\ k \neq j}}^{n} a_{i k}^{(h)} v_{j k}+\sum_{\substack{k=1 \\ k \neq j}}^{n} a_{i j}^{(h)} v_{k j}<0
$$

and, consequently,

$$
u_{i j}<\sum_{\substack{k=1 \\ k \neq j}}^{n} a_{i k}^{(h)} v_{j k}-\sum_{\substack{k=1 \\ k \neq j}}^{n} a_{i j}^{(h)} v_{k j}
$$

Proposition 2 A technical coefficients matrix $\mathbf{A}$ calculated on the basis of $\mathbf{U}=\mathbf{A V}^{\mathrm{T}}$ will not yield negative values when for a nonsingular and nonnegative make matrix $\mathbf{V}$,

$$
\sum_{\substack{k=1 \\ k \neq j}}^{n} a_{i k}^{(h)} v_{j k}<\sum_{\substack{k=1 \\ k \neq j}}^{n} a_{i j}^{(h)} v_{k j}, \quad \forall j
$$

Since $u_{i j} \geq 0$, and assuming

$$
\sum_{\substack{k=1 \\ k \neq j}}^{n} a_{i k}^{(h)} v_{j k}<\sum_{\substack{k=1 \\ k \neq j}}^{n} a_{i j}^{(h)} v_{k j} \quad \text { or } \sum_{\substack{k=1 \\ k \neq j}}^{n} a_{i k}^{(h)} v_{j k}-\sum_{\substack{k=1 \\ k \neq j}}^{n} a_{i j}^{(h)} v_{k j}<0,
$$

then it always occurs that

$$
u_{i j}-\left(\sum_{\substack{k=1 \\ k \neq j}}^{n} a_{i k}^{(h)} v_{j k}-\sum_{\substack{k=1 \\ k \neq j}}^{n} a_{i j}^{(h)} v_{k j}\right)>0
$$

which, according to Proposition 1, implies a nonnegative value of $\mathbf{A}$. The necessity proof does not hold because

$$
u_{i j}-\left(\sum_{\substack{k=1 \\ k \neq j}}^{n} a_{i k}^{(h)} v_{j k}-\sum_{\substack{k=1 \\ k \neq j}}^{n} a_{i j}^{(h)} v_{k j}\right)>0
$$

does not guarantee that (8) will be fulfilled.

As it has been developed so far, negatives still can remain after having solved Almon's algorithm. In fact, the procedure to keep the negatives out of A consists of scaling down all components of the removal term, i.e., the second on the right-hand side of (5), to leave a zero balance. Then the "total-stolen-from-other-industries" term is added gradually and not all at once. This process can be expressed in equations 
introducing in (5) scale factors, $s_{i j}^{(h)}$, which are defined by

$$
s_{i j}^{(h)}= \begin{cases}\frac{u_{i j}}{\sum_{k=1, k \neq j}^{n} a_{i j}^{(h)} v_{k j}} & \text { if } u_{i j}<\sum_{k=1, k \neq j}^{n} a_{i j}^{(h)} v_{k j}, \\ 1 & \text { if } u_{i j} \geq \sum_{k=1, k \neq j}^{n} a_{i j}^{(h)} v_{k j} .\end{cases}
$$

Equation (5) is then replaced by

$$
a_{i j}^{(h+1)} \sum_{k=1}^{n} v_{k j}=u_{i j}-s_{i j}^{(h)} \sum_{\substack{k=1 \\ k \neq j}}^{n} a_{i k}^{(h)} v_{j k}+\sum_{\substack{k=1 \\ k \neq j}}^{n} s_{i k}^{(h)} a_{i j}^{(h)} v_{k j} .
$$

However, as described in [3], only when the removal term is larger than the entry in the use matrix from which it is being removed-that is, when $u_{i j}$ is lower than the negative term on the right-hand side of (5), scaling down is applied to leave a zero balance. Therefore, scale factors should be redefined replacing in $s_{i j}^{(h)}$, $\sum_{k=1 k \neq j}^{n} a_{i j}^{(h)} v_{k j}$ by $\sum_{k=1 k \neq j}^{n} a_{i k}^{(h)} v_{j k}$.

Though by summing both sides of (10) over $j$, it is easy to see that the result is the same no matter what scale factor is defined; economic interpretation of the two latter terms of (10) is guaranteed in case we assume the redefined scale factor. Then, substituting in $(10),{ }^{4}$ we obtain

$$
\begin{aligned}
a_{i j}^{(h+1)} \sum_{k=1}^{n} v_{k j}= & u_{i j}-\left(\frac{u_{i j}}{\sum_{k=1, k \neq j}^{n} a_{i k}^{(h)} v_{j k}}\right) \sum_{\substack{k=1 \\
k \neq j}}^{n} a_{i k}^{(h)} v_{j k} \\
& +\sum_{\substack{k=1 \\
k \neq j}}^{n}\left(\frac{u_{i k} a_{i j}^{(h)} v_{k j}}{\sum_{k=1, k \neq j}^{n} a_{i k}^{(h)} v_{j k}}\right),
\end{aligned}
$$

where it is straightforward that a zero balance is obtained by summing the two former terms of the right-hand side of (11). Finally, (11) results in

$$
a_{i j}^{(h+1)} \sum_{k=1}^{n} v_{k j}=\sum_{\substack{k=1 \\ k \neq j}}^{n}\left(u_{i k} \frac{a_{i j}^{(h)} v_{k j}}{\sum_{p=1, p \neq k}^{n} a_{i p}^{(h)} v_{k p}}\right),
$$

where $a_{i j} v_{k j}$ represents the total inputs of commodity $i$ used for making the secondary product $j$ of industry $k$, and $\sum_{p=1 p \neq k}^{n} a_{i p} v_{k p}$, the total inputs of commodity $i$ used for making all secondary products of industry $k$. Actually, in (12), the total requirements of inputs $i$ needed by industry $k\left(u_{i k}\right)$ is multiplied by the proportion of inputs $i$ used for making secondary outputs of commodity $j$ by industry $k$ over

\footnotetext{
${ }^{4}$ Notice that for scale factor equals to one, (10) becomes (5) and it is easy to see that, by summing both sides of (5) over $j$; the result is given by the total uses of input $i$ by industry $j$.
} 
the total consumption of these inputs for making all secondary products by the same industry. Finally, by summing both sides of (12) over $j$, it yields

$$
\begin{aligned}
\sum_{j=1}^{n}\left(a_{i j}^{(h+1)} \sum_{k=1}^{n} v_{k j}\right) & =\sum_{j=1}^{n} \sum_{\substack{k=1 \\
k \neq j}}^{n}\left(u_{i k} \frac{a_{i j}^{(h)} v_{k j}}{\sum_{k=1, k \neq j}^{n} a_{i k}^{(h)} v_{j k}}\right) \\
& =\sum_{j=1}^{n} u_{i j}\left(\frac{\sum_{j=1, j \neq k}^{n} a_{i j}^{(h)} v_{k j}}{\sum_{p=1, p \neq k}^{n} a_{i p}^{(h)} v_{k p}}\right)=\sum_{j=1}^{n} u_{i j} .
\end{aligned}
$$

As a final result of the iterative process, by the choice of the scalar factors $s$, it is guaranteed that no negative technical coefficients will be obtained. In fact, this procedure actually converges, but it is not clear to what. ten Raa, Chakraborty, and Small [27] criticize this arithmetic manipulation arguing that it goes without justification, is arbitrary, and depends on the choice of $\mathbf{V}$-decomposition as well as the iteration scheme. Notwithstanding these arguments, Almon [3] considers this procedure to be with perfectly reasonable economic interpretation and continues to use it for more than 30 years in the INFORUM model $[2,3]$. Almon's approach is generally used when negatives arise because of the inexactness in make and use tables or because of slight differences in the technologies in different industries. Incidentally, the Belgian input-output tables [5] comprise a commodity-by-commodity input-output table using Almon's procedure to remove the minor negatives that could not be removed manually.

\subsection{Rainer Procedure [16]}

Rainer focuses on the fact that different data setups must be constructed since the purpose of making a homogeneous input-output table differs from the objective of making a descriptive make-use system in terms of National Accounts. Rainer [16] and Rainer and Richter [17] show for the 1976 Austrian use and make tables that when the commodity technology assumption is applied, some negatives can be removed with data rearrangements, but not all of them. The remaining negatives were treated with the industry technology assumption. Basically, in most cases, these data rearrangements consist of giving answer to vertically integrated processes, features underlying classification systems, product mix problems, and others mainly specific of the Austrian economy. In conclusion, data arrangement can be an answer to the problem of negatives when the commodity technology hypothesis is assumed.

\subsection{Activity Technology Model [11]}

Konijn [11] assumes that industries can produce commodities according to several production processes and that the same production process can be used by other industries. Moreover, production processes may have multiple outputs, as in the by-product technology model described in [13]. However, the resulting activity-byactivity input-output table is still not free of negatives. Konijn [11] and Konijn and Steenge [12] argue that remaining negatives clearly indicate that some classification 
Table 1 Stahmer procedure [21]

\begin{tabular}{|c|c|c|c|c|c|c|}
\hline \multirow{5}{*}{ 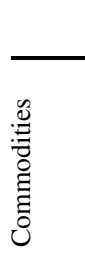 } & \multicolumn{5}{|c|}{ Industries } & \multirow{2}{*}{$\begin{array}{l}\text { Totals } \\
a_{k 1} \sum_{j=1}^{n} v_{j 1}\end{array}$} \\
\hline & $a_{k 1} v_{11}$ & $\cdots$ & $a_{k 1} v_{j 1}$ & $\cdots$ & $a_{k 1} v_{n 1}$ & \\
\hline & $\cdots$ & $\cdots$ & $\cdots$ & $\cdots$ & $\cdots$ & $\ldots$ \\
\hline & $a_{k i} v_{1 i}$ & $\cdots$ & $a_{k i} v_{j i}$ & $\cdots$ & $a_{k i} v_{n i}$ & $a_{k i} \sum_{j=1}^{n} v_{j i}$ \\
\hline & $\cdots$ & $\cdots$ & $\cdots$ & $\cdots$ & $\cdots$ & $\cdots$ \\
\hline & $a_{k n} v_{1 n}$ & $\cdots$ & $a_{k n} v_{j n}$ & $\cdots$ & $a_{k n} v_{n n}$ & $a_{k n} \sum_{j=1}^{n} v_{j n}$ \\
\hline Totals & $u^{k 1}$ & $\cdots$ & $u_{k j}$ & $\ldots$ & $u_{k n}$ & \\
\hline
\end{tabular}

adjustments must be made or some further research on errors data must be developed. Although the need of further information on the use and make system is required to apply the activity technology model, Statistics Netherlands actually adopted this way of removing negatives. In conclusion, Konijn [11] proposes that we explicitly look at production processes instead of commodities and that we take the commodity classification of use and make matrices as an instrument rather than a fixed datum.

\subsection{Steenge Procedure [22]}

Steenge [22] locates errors in such a way that minimal changes are needed to obtain a non-negative technical coefficients matrix. Unlike ten Raa [23] and ten Raa and van der Ploeg [26] — who use a priori estimated errors, Steenge proposes a way to locate errors a posteriori.

The United States available information in [22] was performed with only 14 industries and commodities for 1977, and illustrates how very few corrections are required to obtain make and use matrices such that the commodity technology produces no negative coefficients. However, the adjustments lack statistical significance.

\subsection{Stahmer Procedure [21]}

Stahmer [21] established a modified transformation procedure based on the commodity technology model using special transformation matrices for certain rows and columns and using additional data. The procedure firstly defines a "special transformation table" for a particular input $k$ as shown in Table 1.

According to the commodity technology assumption, technical coefficients for making the same product whatever industry produces them are coincident. Therefore, the output totals in each row are multiplied by the same input coefficient. In matrix terms, Stahmer [21] define a "special transformation matrix" for each input $k$ as shown in Table 1: $\mathbf{S}_{k}=\hat{\mathbf{A}}_{k} \mathbf{V}^{\mathrm{T}}$ where $\hat{\mathbf{A}}_{k}$ represents a diagonal matrix with the elements of the $k$ th row of the technical coefficients matrix in the diagonal. The column totals of each $\mathbf{S}_{k}$ show the use data available before the adjusting procedure and the row totals, the result of the transition process.

Stahmer $[21]^{5}$ proposes to use the special transformation matrix $\mathbf{S}_{k}$ in cases where the commodity technology model generates negatives. With additional available in-

${ }^{5}$ Stahmer [20] originally includes also the value-added row into the use matrix. 
formation, $\mathbf{S}_{k}$ is corrected in such a way that total uses of input $k$ by each industry remain unchanged. However, since during the correction process available data about use or inputs requirements remain unchanged for every industry and commodity input, it may occur that several different input structures for one commodity can be established in certain rows and columns of $\mathbf{A}$, which in fact introduce some distortion in terms of the commodity technology assumption [11]. Actually, the commodity technology hypothesis would not hold any more.

The German Federal Statistical Office applied this procedure for its 1980 inputoutput tables.

\subsection{United States Procedure [31]}

The Bureau of Economic Analysis hybrid procedure [9] first applies the commodity technology assumption to those secondary products that are not suitable for the industry technology model. All the resulting transfers of associated inputs and outputs are made at the same time as the use and make matrices are compiled. Hence, the published use and make tables actually include all these transformations. However, some additional information on inputs structures is also used so that the commodity technology model cannot be applied in a fully mechanical way (redefinition process). The remaining secondary products are then transferred according to the industry technology assumption.

\subsection{Nonnegativity Conditions and Rectangular Matrices}

Konijn [11] and Steenge [22] $]^{6}$ gave a mathematical answer to the question of when we can have a nonnegative matrix $\mathbf{A}$, which satisfies the commodity technology assumption, for given rectangular use and make matrices. That is, a non-negative matrix A exists, satisfying $\mathbf{U}=\mathbf{A} \mathbf{V}^{\mathrm{T}}$, if and only if for any vector $\mathbf{s} \geq 0$ with $\mathbf{V}^{\mathrm{T}} \mathbf{s}>0$, we have Us $\geq 0$ (Mangasarian's theorem). If $\mathbf{s}$ is interpreted as a vector of changes in activity levels, this theorem states that if for some change in industry activity the output of all commodities is increased, then the use of none of the commodities is decreased. Otherwise, a firm could produce more of everything, while using less of something, which is strange according to Konijn [11]. Steenge [22] argues that the resulting technical coefficients matrix only would represent imputed commodity specific input proportions, consistent with the overall use and make tables. Further research by industrial experts on empirical data is required to see if columns of the $\mathbf{A}$ matrix can be interpreted as production functions.

\section{Conclusions: A Guiding Procedure}

Once we have formalized the problem of how to construct a technical coefficients matrix and once we have discussed the different problems and solutions given to the drawbacks underlying the commodity technology model when the construction of a

\footnotetext{
${ }^{6}$ For a full description of all theorems and propositions see p. 380 in [22] and pp. 139-142 in [11].
} 
technical coefficients matrix is the main purpose, we conclude providing a guiding procedure.

Three reasons support the use of the commodity technology model. First, at a microlevel data, the commodity technology model seems to be a useful working hypothesis according to the tests provided in [15] and in [19]. Hence, disaggregation is commendable. Second, as shown in [22] and [11], it is theoretically possible to find a nonnegative technical coefficients matrix consistent with the make-use system (even with rectangular use and make matrices), provided some adjustments are made. And third, the commodity technology assumption fulfills the axioms of Kop Jansen and ten Raa [13].

Therefore, it seems that a commonly and desirable guide to proceed in order to construct technical coefficients matrices would consist in applying the commodity technology assumption, using afterward location methods for errors of measurement (although these adjustments may be rejected statistically, they are supposed to be accepted by industrial experts) or negatives as indicators of errors of measurement and/or aggregation problems. Once these problems are solved, no more negatives should arise. It is desirable to use the industry technology assumption just in the needed cases.

\section{Competing Interests}

The authors declare that they have no competing interests.

Acknowledgements This paper was conceived at Tilburg University, being J.M. Rueda-Cantuche a visiting fellow at the Centre for Economic Research (CentER). J.M. Rueda Cantuche's research has been made possible by a grant of the Regional Education and Science Ministry of Andalusia (Spain) and the economic support of the Pablo de Olavide University at Seville (Spain). Comments by two anonymous referees improved the paper.

\section{References}

1. Almon C (1970) Investment in input-output models and the treatment of secondary products. In: Carter AP, Brôdy A (eds) Applications of input-output analysis. North-Holland, Amsterdam

2. Almon C (1991) The INFORUM approach to interindustry modelling. Econ Syst Res 3:1-8

3. Almon C (2000) Product-to-product tables via product technology with no negative flows. Econ Syst Res 12:27-43

4. Armstrong AG (1975) Technology assumptions in the construction of United Kingdom input-output tables. In: Allen RIG, Gossling WF (eds) Estimating and updating input-output coefficients. InputOutput Publishing Co, London

5. Avonds L, Gilot A (2002) The new Belgian input-output table-general principles. Paper presented at the Fourteenth International Conference on Input-Output Techniques, Montreal, Canada, 10-15 October. http://www.iioa.org/pdf/14th\%20conf/Avonds8.pdf

6. de Mesnard L (2004) Understanding the shortcomings of commodity-based technology in inputoutput models. An economic circuit approach. J Reg Sci 44:125-141

7. Edmonston JH (1952) A treatment of multiple-process industries. Q J Econ 66:557-571

8. Gigantes T (1970) The representation of technology in input-output systems. In: Carter AP, Brôdy A (eds) Contributions to input-output analysis. North-Holland, Amsterdam

9. Guo J, Lawson AM, Planting MA (2002) From make-use to symmetric I-O tables: an assessment of alternative technology assumptions. Working paper 2002-03, Bureau of Economic Analysis. http://www.bea.gov/papers/pdf/alttechassump.pdf 
10. Konijn PJA (1991) Aggregation in the commodity technology model. Österr Z Stat Inform 21:39-56

11. Konijn PJA (1994) The make and use of commodities by industries: on the compilation of inputoutput data from the national accounts. University of Twente, Enschede

12. Konijn PJA, Steenge AE (1995) Compilation of input-output data from the National Accounts. Econ Syst Res 7:31-45

13. Kop Jansen PSM, ten Raa T (1990) The choice of model in the construction of input-output coefficients matrices. Int Econ Rev 31:213-227

14. Mattey JP (1993) Evidence on input-output technology assumptions from the longitudinal research database. Discussion paper 93-8, Centre for Economic Studies, US Bureau of the Census, Washington, DC

15. Mattey JP, ten Raa T (1997) Primary versus secondary production techniques in US manufacturing. Rev Income Wealth 43:449-464

16. Rainer N (1989) Descriptive versus analytical make-use systems: some Austrian experience. In: Miller R, Polenske K, Rose AZ (eds) Frontiers of input-output analysis. Oxford University Press, New York

17. Rainer N, Richter J (1992) Some aspects of the analytical use of descriptive make and absorption tables. Econ Syst Res 4:159-172

18. Rueda-Cantuche JM, ten Raa T (2009) The choice of model in the construction of industry coefficients matrices. Econ Syst Res 21:363-376

19. Rueda-Cantuche JM, ten Raa T (2013) Testing assumptions made in the construction of input-output tables. Econ Syst Res. doi:10.1080/09535314.2013.774265

20. Stahmer C (1982) Connecting national accounts and input-output tables in the Federal Republic of Germany. In: Skolka J (ed) Compilation of input-output tables. Springer, Berlin

21. Stahmer C (1985) Transformation matrices in input-output compilation. In: Smyshlyaev A (ed) Inputoutput modelling. Springer, New York

22. Steenge AE (1990) The commodity technology revisited: theoretical basis and an application to error location in the make-use framework. Econ Model 7:376-387

23. ten Raa T (1988) An alternative treatment of secondary products in input-output analysis: frustration. Rev Econ Stat 70:535-540

24. ten Raa T, Rueda-Cantuche JM (2003) The construction of input-output coefficients matrices in an axiomatic context: some further considerations. Econ Syst Res 15:439-455

25. ten Raa T, Rueda-Cantuche JM (2007) A generalized expression for the commodity and the industry technology models in input-output analysis. Econ Syst Res 19:99-104

26. ten Raa T, van der Ploeg R (1989) A statistical approach to the problem of negatives in input-output analysis. Econ Model 6:2-19

27. ten Raa T, Chakraborty D, Small JA (1984) An alternative treatment of secondary products in inputoutput analysis. Rev Econ Stat 66:88-97

28. United Nations (1968) A System of National Accounts. Studies in Methods Series F, no 2, rev 3. New York

29. United Nations (1999) Handbook of Input-Output Table Compilation and Analysis. Studies in Methods Series F, no 74. New York

30. United Nations, EUROSTAT, IMF, OECD, WB, (1993) A System of National Accounts 1993. Brussels-Luxembourg, New York, Paris, Washington, DC

31. Young PC (1986) The US input-output experience-present status and future prospects. In: Franz A, Rainer N (eds) Problems of compilation of input-output tables. Orac, Vienna 